\title{
Can immune reprogramming with alemtuzumab induce permanent remission in multiple sclerosis?
}

Heinz Wiendl, MD, PhD

Dennis Bourdette, MD

Olga Ciccarelli, MD, PhD, FRCP

Correspondence to

Dr. Wiendl:

heinz.wiendl@ukmuenster.de

Neurology ${ }^{\circledR} 2017 ; 89: 1098-1100$

See pages 1107 and 1117
Disease-modifying therapies (DMTs) for multiple sclerosis (MS) have developed tremendously over the last 2 decades. Currently, more than 16 different products targeting various immunologic components have been approved for MS treatment in several countries.

The high number of MS treatments has made the management of patients increasingly complex. Two main therapeutic strategies are currently adopted in the clinical setting: (1) escalation (or optimization) therapy or (2) induction (or immune reset) therapy (figure). In the escalation/optimization strategy, alemtuzumab is recommended as a second- or third-line therapy to patients who have had an inadequate response to initial DMTs. In the induction strategy, it has instead been argued by some investigators that alemtuzumab should be used as a first-line agent with the intention of inducing long-term disease stability. However, long-term follow-up studies are needed to know what percentage of patients have a durable response to alemtuzumab without the development of severe side effects.

Alemtuzumab is an immune-depleting therapy that has 3 major parts to its mechanism of action: (1) selective targeting of CD52 on T and B cells, and to a lesser extent, innate immune cells; (2) immediate depletion of immune cells; and (3) perhaps the most important and least understood part, a phase of immune cell repopulation. Depletion of CD52+ immune cells occurs mainly in the periphery and subsequent effects are translated to the CNS. ${ }^{1}$ Investigation of the long-term effects of alemtuzumab on various subtypes of immune cells, such as $\mathrm{T}$ effector memory and resident memory $\mathrm{T}$ cells, illustrates aspects of repopulation and immune reprogramming. ${ }^{2}$ The drug administration route and dosing, the persistently low CD4 and CD8 T-helper cell levels, and the occurrence of secondary autoimmunity during the phase of immune cell repopulation suggest that alemtuzumab induces a reprogrammed immune repertoire. Alemtuzumab thus might produce a durable therapeutic response as a consequence of a permanent rebalancing of the immune system.
In this issue of Neurology ${ }^{\circledR}$, Havrdova et al. ${ }^{3}$ and Coles et al. ${ }^{4}$ report efficacy and safety results of 3year extension studies of both Comparison of Alemtuzumab and Rebif Efficacy in Multiple Sclerosis I and II (CARE-MS I and II) trials. These were 2year, phase III, randomized, active-controlled trials that compared alemtuzumab with interferon- $\beta-1$ a in patients with relapsing-remitting $\mathrm{MS}$ and active disease (defined as $\geq 2$ relapses in the last 2 years and $\geq 1$ relapse in the last year). The main difference between the 2 trials is that CARE-MS I patients had never received disease-modifying treatment, while CARE-MS II patients had relapsed after prior treatment with other therapies. In both, treatment with alemtuzumab consisted of 5 daily 12 $\mathrm{mg}$ infusions at the start of therapy, and another round occurring 1 year later consisting of 3 daily $12 \mathrm{mg}$ infusions. Analysis of the extension studies showed that the annualized relapse rate at 5 years was 0.15 in CARE-MS I and 0.18 in CARE-MS II. The cumulative fraction of participants with no evidence of clinical and MRI disease activity over years 3-5, referred to as no evidence of disease activity (NEDA), was 39.5\% in CARE-MS I and $27 \%$ in CARE-MS II. Importantly, $67.3 \%$ and $55.5 \%$ of participants enrolled into the extension studies did not require any DMT over 3 years after the second alemtuzumab treatment, and it can be argued that they were experiencing a drugtreatment-free remission (figure); the remaining $32.7 \%$ and $44.5 \%$ of patients received treatment with alemtuzumab or another DMT. A total of $33 \%$ and $42.9 \%$ of patients showed a confirmed disability improvement (defined as $\geq 1$-point Expanded Disability Status Scale decrease from a baseline score $\geq 2.0$ ) over 5 years. The median yearly brain parenchymal fraction change was -0.2 in the extension of CARE-MS I and -0.07 in the extension of CARE-MS II.

These efficacy results must be considered with some caution, however, considering that there are biases typical of extension studies with open-label designs, including the lack of blinding and the lack of

From the Department of Neurology (H.W.), University of Muenster, Germany; Department of Neurology (D.B.), Oregon Health \& Science University, Portland; and Department of Neuroinflammation (O.C.), UCL Institute of Neurology, University College London, UK.

Go to Neurology.org for full disclosures. Funding information and disclosures deemed relevant by the authors, if any, are provided at the end of the editorial. 
A. Chronic therapies

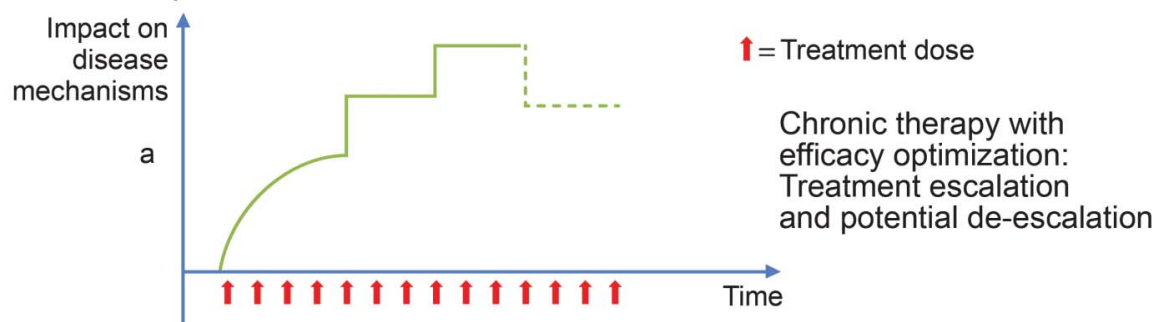

b

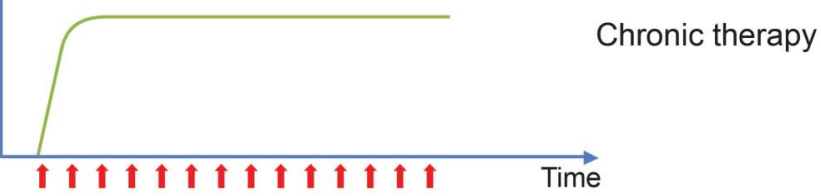

B. Induction therapies

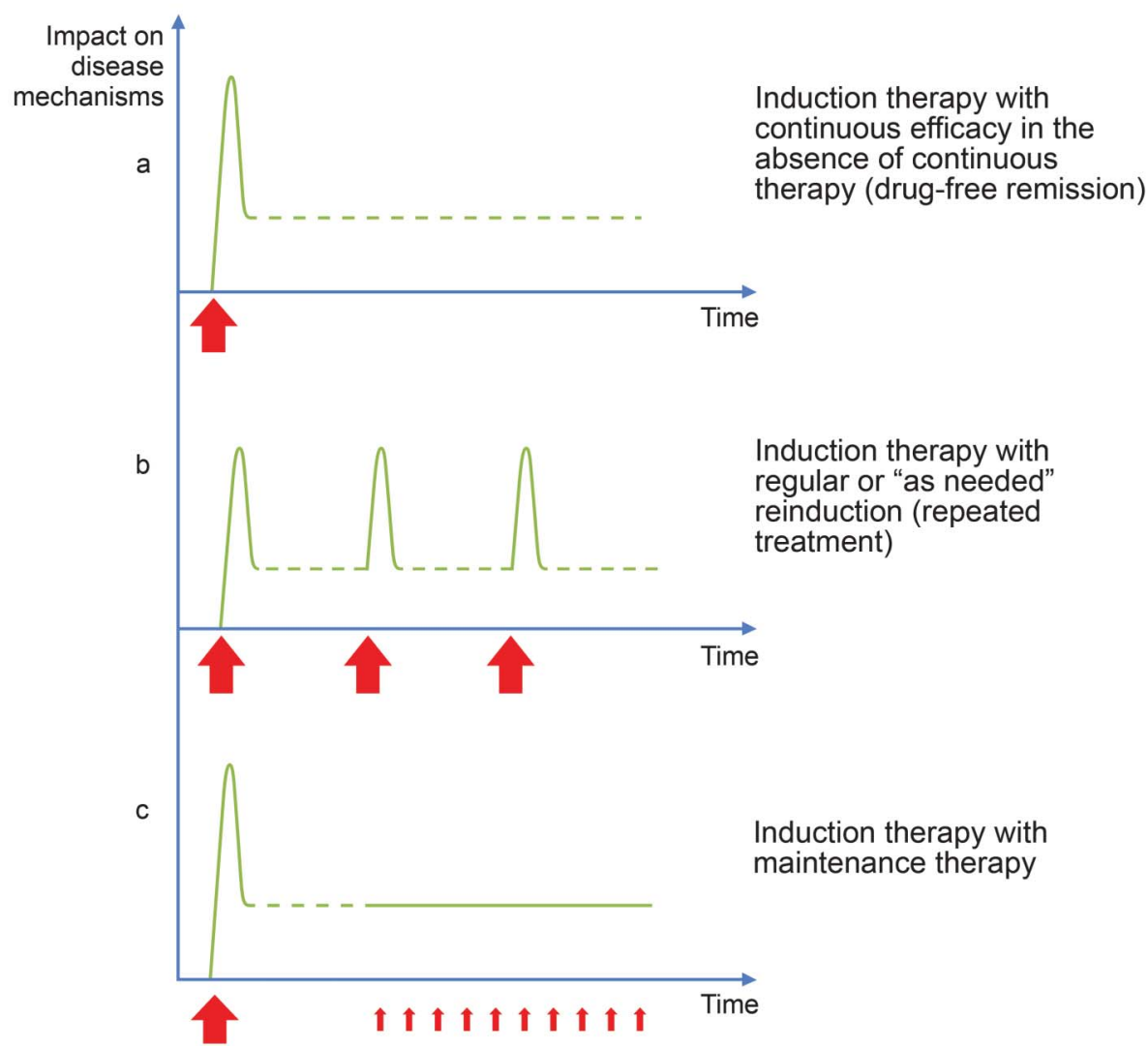

(A) Chronic therapy strategies requiring the continuous application of treatments over time, with a possibility for optimization/escalation of treatment. (B) Induction therapies are applied with less frequent and more disease pathogenesis intervening doses that are followed by a no continuation therapy (a), repeated induction treatments on a regular or as-needed basis (b), or maintenance therapy with maintenance treatment (c).

a control group. In addition, $4.9 \%$ of CARE-MS I patients and $7.1 \%$ of CARE-MS II patients declined to be enrolled in the extension studies; while this is an unusually high enrollment rate for an extension study, these percentages should be kept in mind and perhaps subtracted from the reported rates of NEDA and percentage of patients who did not require treatment with a DMT over the 3 years after alemtuzumab treatment. Since the decision to continue treatment with alemtuzumab or any other drug was left to the treating physicians and patients, patients may have remained untreated despite disease progression (which was permissible in the extension study), and the opinions of nonblinded investigators could have influenced the detection of disease activity. 
Extension studies are undoubtedly useful in improving our knowledge of side effects of new medications. This is especially relevant for alemtuzumab, whose key adverse events include infusion reactions, immune-mediated thyroid disease, immune thrombocytopenia (ITP), and glomerulonephritis. Alemtuzumab may also be associated with other serious complications, as suggested by recent cases of Listeriosis monocytogenes, cytomegalovirus syndrome, pulmonary and CNS nocardiosis, and B-cell-mediated CNS disease. ${ }^{5-7}$ Both extension studies reported new findings in respect to the core studies, which included a substantial risk of herpes zoster reactivation, with 25 new cases in the extension of CARE-MS I and 35 cases in the extension of CARE-MS II, and a relatively high 5-year incidence of thyroid autoimmunity (40.7\% and 37.7\%, respectively). Particular attention should be given to papillary thyroid carcinoma, with 1 new case in the extension of CARE-MS I and 2 new cases in the extension of CARE-MS II. Eleven new cases of ITP occurred overall in the extension studies and 1 case of nephropathy was seen at year 3 in the extension of the CARE-MS I trial. Whether additional serious adverse events will develop beyond 3 years after the last infusion of alemtuzumab remains to be determined.

Overall, the extension studies of CARE-MS I and CARE-MS II trials suggest that therapy-free remission can be achieved in over $50 \%$ of patients following 2 courses of alemtuzumab, indicating that a sustained immunologic reprogramming of the disturbed immune repertoire can be achieved in many patients. Further follow-up is needed to determine how long this immunologic reprogramming will last. Several challenges remain in the use of alemtuzumab. These include the need to identify prognostic biomarkers that identify patients who are more likely to benefit from an induction treatment strategy and the need for longer observation periods to confirm the safety profile of alemtuzumab, which is crucial in selecting this drug over another highly efficacious therapy, natalizumab. ${ }^{8}$ An interesting question that, if addressed, may shed some light into the pathogenesis of MS is why some patients show disease worsening despite immune-depleting therapy.

The possibility of inducing a long-term or even permanent drug-free remission in people with relapsingremitting MS with alemtuzumab is exciting and novel in MS therapy. The challenge is to define which patients warrant treatment with this potent therapy and identifying ways to mitigate serious side effects.

\section{ACKNOWLEDGMENT}

The authors thank Heike Blum for drawing the figure and Nick Fulcher for language editing.

\section{STUDY FUNDING}

H.W.'s work is supported by the German Research Foundation (DFG) and the Ministry of Education and Research (BMBF, the German Competence Network MK, KKNMS). D.B. receives research funding from the U.S. National MS Society. O.C. receives funding from UK MS Society and Rosetree Trust and her work is supported by NIHR UCLH BRC.

\section{DISCLOSURE}

Heinz Wiendl: honorarium for acting as a member of scientific advisory boards and as a consultant for Biogen, Evgen, MedDay Pharmaceuticals, Merck Serono, Novartis, Roche Pharma AG, and Sanofi-Genzyme; speaker honoraria and travel support from Alexion, Biogen, Cognomed, F. Hoffmann-La Roche Ltd., Gemeinnützige Hertie-Stiftung, Merck Serono, Novartis, Roche Pharma AG, Sanofi-Genzyme, TEVA, and WebMD Global; paid consultant for AbbVie, Actelion, Biogen, IGES, Novartis, Roche, Sanofi-Genzyme, and the Swiss Multiple Sclerosis Society; and research funded by the German Ministry for Education and Research (BMBF), Deutsche Forschungsgesellschaft (DFG), Else Kröner Fresenius Foundation, Fresenius Foundation, Hertie Foundation, NRW Ministry of Education and Research, Interdisciplinary Center for Clinical Studies (IZKF) Muenster and RE Children's Foundation, Biogen GmbH, GlaxoSmithKline GmbH, Roche Pharma AG, and Sanofi Genzyme. Dennis Bourdette: research grants from the US National MS Society. O.C. serves as a consultant for Biogen, Teva, SanofiGenzyme, Roche Pharma AG, Novartis, and GE Healthcare, and she is an associate editor of Neurology. Go to Neurology.org for full disclosures.

\section{REFERENCES}

1. Turner MJ, Lamorte MJ, Chretien N, et al. Immune status following alemtuzumab treatment in human CD52 transgenic mice. J Neuroimmunol 2013;261:29-36.

2. Rosenblum MD, Way SS, Abbas AK. Regulatory T cell memory. Nat Rev Immunol 2016;16:90-101.

3. Havrdova E, Arnold DL, Cohen JA, et al. Alemtuzumab CARE-MS I 5-year follow-up: durable efficacy in the absence of continuous MS therapy. Neurology 2017;89: 1107-1116.

4. Coles AJ, Cohen JA, Fox EJ, et al. Alemtuzumab CAREMS II 5-year follow-up: efficacy and safety findings. Neurology 2017;89:1117-1126.

5. Clerico M, De Mercanti S, Artusi CA, Durelli L, Naismith RT. Active CMV infection in two patients with multiple sclerosis treated with alemtuzumab. Mult Scler 2017;23: 874-876.

6. Penkert H, Delbridge C, Wantia N, Wiestler B, Korn T. Fulminant central nervous system nocardiosis in a patient treated with alemtuzumab for relapsing-remitting multiple sclerosis. JAMA Neurol 2016;73:757-759.

7. Haghikia A, Dendrou CA, Schneider R, et al. Severe B-cellmediated CNS disease secondary to alemtuzumab therapy. Lancet Neurol 2017;16:104-106.

8. Kalincik T, Brown JWL, Robertson N, et al. Treatment effectiveness of alemtuzumab compared with natalizumab, fingolimod, and interferon beta in relapsing-remitting multiple sclerosis: a cohort study. Lancet Neurol 2017;16: 271-281. 


\section{Neurology}

\section{Can immune reprogramming with alemtuzumab induce permanent remission in multiple sclerosis?}

Heinz Wiendl, Dennis Bourdette and Olga Ciccarelli

Neurology 2017;89;1098-1100 Published Online before print August 23, 2017

DOI 10.1212/WNL.0000000000004381

\section{This information is current as of August 23, 2017}

\section{Updated Information \& Services}

References

Citations

Subspecialty Collections

Permissions \& Licensing

Reprints including high resolution figures, can be found at: http://n.neurology.org/content/89/11/1098.full.html

This article cites 8 articles, 2 of which you can access for free at: http://n.neurology.org/content/89/11/1098.full.html\#\#ref-list-1

This article has been cited by 1 HighWire-hosted articles: http://n.neurology.org/content/89/11/1098.full.html\#\#otherarticles

This article, along with others on similar topics, appears in the following collection(s):

\section{All Clinical trials}

http://n.neurology.org//cgi/collection/all_clinical_trials Multiple sclerosis

http://n.neurology.org//cgi/collection/multiple_sclerosis

Information about reproducing this article in parts (figures,tables) or in its entirety can be found online at:

http://n.neurology.org/misc/about.xhtml\#permissions

Information about ordering reprints can be found online:

http://n.neurology.org/misc/addir.xhtml\#reprintsus

Neurology ${ }^{\circledR}$ is the official journal of the American Academy of Neurology. Published continuously since 1951, it is now a weekly with 48 issues per year. Copyright () 2017 American Academy of Neurology. All rights reserved. Print ISSN: 0028-3878. Online ISSN: 1526-632X.

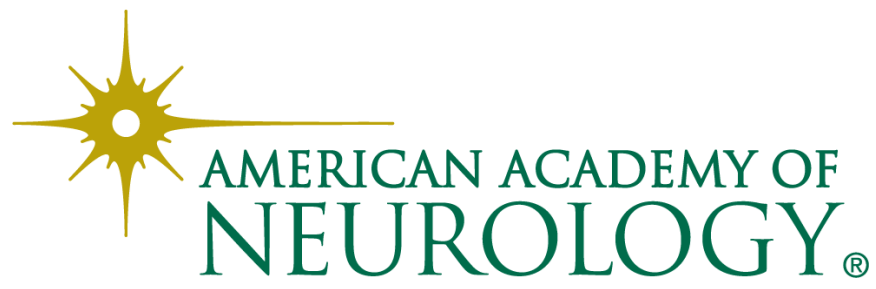

